\title{
Misanthropic Attitude of George Orwell's Animal Farm: from Revolution to
}

\author{
Rehabilitation \\ * Sami Ullah Khan, Vice Principal (Corresponding Author) \\ ** Dr. Abdus Samad, Assistant Professor \\ *** Amar Yasir, PST
}

\begin{abstract}
This paper aims to focus on finding and highlighting the misanthropic aspects and their effects on the characters in the novel Animal Farm by George Orwell. The misanthropic perspectives in the novel have been premeditated deeply. Misanthropy has been implemented on the characters. The characters like, Old Major, Napoleon, Squealer, and others have been studied to manifest the misanthropic attitudes in it. Old major is the father of misanthropy in the novel Animal Farm and gives the idea of rehabilitation in the animals' lives and Napoleon accomplishes it. The disgusting behavior of the animals leads to revolution. Misanthropy affects humans' lives and they become homeless. The findings of the paper are that the animals possess disgusting behavior against humans. The paper concludes that the whole novel is replete with misanthropy and it is the very aspect that has been probed by this article. Eventually, misanthropy proves to be a nightmarish dream for animals of the Animal Farm and a complete disillusionment they expect from the revolution.
\end{abstract}

Keywords: Misanthropy, George Orwell, Animal Form, Revelation, Rehabilitation

Introduction

Eric Arthur Blair was born in Bengal, India; on June 25, 1903, where his father worked. He was a dexterous essayist, celebrated novelist, and a prominent critic. He was the writer of the most famous dystopian novels like Animal Farm and the Nineteen Eighty-Four. He had strongly manipulated some of the major political movements such as Imperialism, Fascism, and Communism in his work. His pseudonym was George Orwell. George Orwell wrote 'Animal Farm' in such an era, where humanity was destructed by two world wars, and such an environment invoked Orwell to write Animal Farm in the raging background Nazism and Communism. The novel itself is replete with misanthropic elements and changes the lives of the characters in the novel due to the misanthropy. Animal Farm Orwell's expeditious but very impressive novel scrutinizes how a farm of suppressed and neglected animals' defiance against their owner who utilizes them in a very humiliating way. Animal Farm is a factious work of George Orwell which was written between 1943-1944 and was initially rejected by many publishers but finally got published on August 17, 1945.

The character of Old Major, Napoleon, and others have been evaluated and seen that how Old Major changes the thoughts and ideology of the animals using language power and how he has developed the theory of animalism among the animals. The most important and essential phenomena that have been discussed in this paper are the effects and outcomes of the misanthropic behavior that has occurred in the novel and how these outcomes affect the lives of animals and humans. There has been seen that the revolt of the animals against humans is just only a revolution not rehabilitation in the lives of the animals.

This research paper portrays the glimpse of misanthropic characters in the novel Animal Farm. Old Major, Benjamin, Boxer, Clover, Mosses, Bluebell, Jessie, and Pincher are cynical and discord with humans. In every speech of animals, it is felt that they want to expel humans from the earth. For instance, Old Major, a prize Middle White Boar: 'a dream of the earth as it will be when Man has vanished' (p.12). It is also the hunger desire of all animals to abolish mankind from the

\footnotetext{
* GHS Sial Bhakkar Email: sami9177d@gmail.com

** Department of English, Kohat University of Science and Technology, Kohat

Email: samadgmm@yahoo.com

*** DHAP Sial
} 
planet and every effort to prove it practically. The glimpse of misanthropy can be found at the surface level in the novel. A misanthropic character produces hatred against the existing creature. In the novel, every character is indulged in a cynical crime. This paper discourages the writers who are fallen in disgusting behavior intensively in their compositions. Present writers are writing their disgusting plays, novels, and poetic works which spread horror, pessimism, and wrong belief among the people. They want to expose the actuality of a society and their way of exposing is contemptuous. The research holds the significance in such a way that it traces the misanthropic elements in the Novel. It has been seen, how the language of the speaker inclines the animals towards misanthropic behavior and misanthropic behavior further leads to revolt against humans. In this article, it has been explored that how every character of the novel has been changed due to misanthropy. It has also been explored in the present study that misanthropic behavior caused to lead the revolution or rehabilitation in the lives of animals and further has been analyzed the outcomes of revolt in the lives of humans and animals.

\section{Literature Review}

George Orwell (1903-1950) adores much reputation through his work. However, he has not written so much but his writings are the pivot for the critics. In the work of George Orwell, there is much evident fluctuation like the paradoxical situation when compared with his biography as well as his direct message in his writing. He has seen many ups and downs and learns a lot of experiences from his life. All these experiences are put on the surface of the pages in a fiction and poetic farms. Therefore, it can be seen the very aspects of pessimism in his works.

Bloom (2009) truly argues that Orwell presents a very silly idea about communism and the character Benjamin is the true image of cynicism. So, Benjamin is the reflection of hating, disgusting and cynical elements. He yells that Orwell in his latest satire wants to develop the reformative aspects but unsuccessfully creates the bitter idealism for human beings. The idealism is free from the ray of hope. All these aspects have caused the nadir of sarcasm. (Bloom, 2009)

Morse (2009) argues "Animal Farm is a fantastic knock at the door of beast that lives inside every human and animal" (Morse, p.85-92).

Paden (2011) advocates inclusiveness in Animal Farm extracting a view that Animal Farm is enriched with different narratives the novel Animal Farm is a true fable which gives the best moral lesson 'in its significance ranging from Aesop-like fable to a modern world communist state'. (Paden, p.49-55)

Meyer (2001) comes to the surface with a statement that the novel Animal Farm is a political allegory in which Orwell (1903-1950) wants to expose the political hypocrisy. Orwell puts his views against the Russian revolution in which at the initial stage, revolutionary leaders seemed to be the well-wisher of the people of that society. After achieving the targets, they participated in the wrong activities and exploited the masses in a humiliated and pitiable way. 'Animal Farm' is overall a political allegory; finding a common contempt against communism and Russia' (Mayer, p.65-84)

However, many critics give their solid arguments about the novel that the novel is against the Soviet Union. Some argue that the novel is a political satire in which every character resembles a unique politician. Some of them are called the novel as a fable and allegory. However, their judgments and proofs for the novel are crucial and essential in the review of literature.

\section{Findings and Discussion}

The novel Animal Farm is a masterwork of George Orwell. Many evidences of misanthropic behaviors have been found for humans in the novel. Misanthropic elements are discovered obviously in the novel. This is enriched with many a misanthropic attitude. From the very beginning, animals develop a particular attitude of contempt towards human beings which results in a strong plane of misanthropy. The present paper portrays the misanthropic posture of George Orwell (1945) in Animal Farm. The attitude of George Orwell (1945) teems with misanthropy in the text. However, the novel is a political satire but misanthropic aspects can be noted obviously.

\section{Misanthropic Attitude in the Speech of Old Major}

Old Major is the major source of this feeling in the beginning. He becomes the main source of light for misanthropic attitude. His misanthropic attitude can be explored from his first speech which is full of hatred, malice, grumble and aversion against mankind and it follows the misanthropy that prevails in the novel. Old Major disgusting and detesting attitude towards humans reaches the peak. He produces much hatred against the crown of the creatures among the animals. His every single word is 
filled with hardness and rudeness. The character of Old Major is there presented as the major misanthropic character in the novel. He is arguing that peace, calm, hunger, and the other problems only cannot be solved when the existence of mankind on the earth is present. Old Major persuades to the whole animal in this way,

"Man is the only real enemy we have. Remove Man from the scene and the root cause of hunger and overwork is abolished forever" (Orwell, p.28).

Further Old Major announces "Man is the only creature that consumes without producing" (Orwell, p.28).

The hardworking and struggling men are severely attacked by the animals. Old Major says that only the animals are serving the world. All the fatigue and burden of humans are done by animals. So, here the cynical behavior of Old Major targets human efforts. According to Old Major, men are parasites. He does not create and produce anything but while using, he is the owner of all the assets. He misuses all the blessings and does not take care of the privilege of the other creatures. He gets a lot of benefits from the other creatures of the whole world but uses them without gratitude. Old Major targets directly to human's body structure and charge blame for their physical weakness.

He addresses to cows and says that, "Every drop of it has gone down the throats of our enemies" (Orwell, p.29)

There can be found a glimpse of misanthropic elements in that line. He calls to humans 'enemies' and tries to betray other animals from humans. He wants to say the word 'enemies' to establish the disgusting ground against humans. He forbids broadly to the comrades and tells them about their importance that the humans only utilized and exploited them. They have no talent to generate and fabricate things. Old Major again wants to flow the cynical waves among the comrades. The fate of the animal depends on the mood and attitude of humans. It has been shown here that the man is wanton and barbarically killed the animals. Humans exploit the animals in their entire life and the end, animals are slaughtered. Here, the misanthropic elements in the character of Old Major reaches on climax. He emphasizes that the enmity against humans should pertain to his death. The campaign of hatred for mankind should be carried generation by generation. The misanthropic behavior is elaborated again in his speech and says, "I merely repeat remember always your duty of enmity towards Man and all his ways" (Orwell, p.30)

The misanthropic elements are tinted when the Old Major tells to animal that the maintenance of antagonism for humans is the duty of all animals. If they want to spend satisfactory life, then they have to perform their duty according to the law of animalism. The glimpse of misanthropy can be noted obviously when Old Major stresses to comrades, "Whatever goes upon two legs is an enemy" (Orwell, p.31)

So, the character of Old Major is the embodiment of misanthropy. He is not only the misanthropic character but also tries to spread the misanthropic aspects among the animals. The misanthropic impression and outcomes of the speeches of Old Major put the long-lasting effects not only humans live but also on animals.

\section{Misanthropy in Seven Commandments}

Seven commandments of animals are pregnant with misanthropic attitudes. However, they educate all the animals on a limited level to instruct the seven commandments and law of animalism. The instructions and educations relating to animals are the abstract of misanthropy. Every word of the seven commandments is the reflection of detesting behavior. These seven commandments change the lives of the animals and prove harmful for humans.

The first commandment represents the sickening performance of animals and the toleration of men on the earth is ill for them. The script, "Whatever goes upon two legs is an enemy" (Orwell, p.42)

Here, the flood of misanthropic behavior is flowing in a severe look. The physiques that are relating to humans are disliked and it becomes the rule of animalism.

Killing is always associated with men. It is shown here that mankind is cruel by nature. No animal shall kill any other animal. Their misanthropic attitude argues to develop the opinion that equality is not found amongst mankind so their slogan raises, "All the animals are equal" (Orwell, p.42)

The commandment in which the animals are united against humans and also enlarge their group for humans is, "Whatever goes upon four legs, or has wings, is a friend" (Animal Farm, p.42) 
In this commandment, it is judged that all the creatures of the world except humans are friends. They want to become more powerful at any cost than humans. The mental tranquility of the comrades is found in the painting of mankind. The commandments are read by Napoleon again and again to ascertain the enmity against humans. The principles and laws that are mentioned in animalism are completely inauspicious and harsh for humans. The disgusting attitude to humans again is glanced when animals change the name of 'Manor Farm' into 'Animal Farm'. They do not dare to endure the name of the farm that Mr. Jones is chosen for the farm's identity. The animals only disgust the humans Skelton and they ironically adopt the vices and evils for humans. It is embellished that, "Nobody stole, nobody grumbled over his rations, the quarreling and biting and jealousy which had been normal features of life in the old days had almost disappeared" (Orwell, p.45)

It is noted that the vices that are mentioned especially in which distrust, stinging, aggressive attitude are discovered in the personality of the leader of the farm. The dream of a utopian world is seen here on the top of the level. It seems that no one finds himself in any difficulty and destitution but the reality is opposed to the facts. It is demonstrated in history that the world is the embodiment of social evils. The animal's expectations are risky and precarious for humans. The desire and wish of the animals can be seen from the text, "When the human race had been finally overthrown" (Orwell, p.46)

They do not contain in the vanishing to Mr. Jones. They want to exterminate humanity from the world. Humans become unbearable and intolerable creatures for comrades. They establish the committees to sustain the enmity against humans. Snowball takes the responsibility to make the committee, "Snowball also busied himself with organizing the other animals into what he called Animal Committees" (Animal Farm, p.47)

Some animals have demonstrated loyalty and faithfulness for Mr. Jones. Snowball and Squalor get a job as a propagandist. Snowball decreases the seven commandments into a short form. Some animals cannot understand the seven commandments. They reduce the seven commandments into a single sentence, "TWO LEGS BAD, FOUR LEGS GOOD" (Orwell, p.49)

Humans have two legs and it is given the title of 'BAD' to them. The antagonism between humans and animals are exposed clearly. The entire creatures of the world having four legs are harmless. The creatures that have two legs are harmful and dangerous for the world. Orwell deems cynically that humans are fundamentally insatiable, selfish, and ravenous by nature. The irony can be seen here that the idea of a utopian world collapse. Napoleon and Snowball always disagree on every point of view, "But it was noticed that these two were never in agreement: whatever suggestion either of them made, the other could be counted on to oppose it" (Orwell, p. 48).

Seven commandments play a very stimulating role in constructing the misanthropic behavior against humans lives.

\section{Misanthropic attitude of Napoleon}

The misanthropic attitude of Napoleon is that he does not trust Snowball due to having human characteristics. Any destruction that occurs at the farm is charged by Snowball after the repulsion of Snowball. It is exaggerated by Squealer that Snowball is the spy of a human being. The misanthropic glimpse can be seen when the windmill is crushed by the storm, they charge blame to humans and Snowball. Napoleon decides that, "Comrades," he said quietly, "do you know who is responsible for this? Do you know the enemy who has come in the night and overthrown our windmill? SNOWBALL" (Orwell, p.77)

The clever Napoleon sentences death to human beings by commanding "Fredrick should be boiled alive". The harshest misanthropic attitude can be seen here.

The misanthropic attitude of Napoleon against humans like Mr. Jones and animals that have humans' traits like Snowball is very pitiable. After expelling Mr. Jones from the Farm, Napoleon becomes the leader of the Farm. He uses the misanthropic perspectives as a weapon to run his Farm. It can be seen that he succeeds to do so.

\section{Revolt and Rehabilitation}

Old Major gives the idea of animalism and in his first speech; he tries to describe the obstacles that the animals face during the region of Mr. Jones. Old Major illustrates these difficulties in this way," our lives are miserable, laborious, and short. We are born; we are given just so much food as will keep the breath in our bodies" (Orwell, p.2). 
These inspiring words motivate all the animals and he succeeds to convey his disgusting message among the animals. It shows a glimpse of prosperity and all the animals prepares to take the revolution at the farm.

After the death of Old Major, Napoleon and other misanthropic animals remain busy taking a revolution based on rehabilitation. When all the animals expel Mr. Jones from the Farm, there cannot be seen any change in their lives. Especially, the working class of the farm is exploited by the leaders of the farm.

Napoleon uses misanthropy as a tool against humans and also succeeds to take the revolution. The objectives of the revolution are the rehabilitations but there cannot be seen any change in the lives of the animals after the revolution that "As for the others, their life, so far as they knew, was as it had always been. They were generally hungry". (Orwell, p.50) It can be seen that the basic necessity of the lives cannot be fulfilled by Napoleon. So, it is only revolt against humans but there cannot be viewed any rehabilitation in the lives of the animals. Their life standards remain the same "there was nothing with which they could compare their present lives:" (Orwell, p.50).

The animals argue about their lives in this way "the animals worked like slaves" (Orwell, p.69). It means that working fatigue is increased after the revolution. They lament on their persisting fate and they consider the best period of Mr. Jones.

Misanthropic behavior of Napoleon does not stop here; he reduces the ratio of the animals, "any animal who absented himself from it would have his rations reduced by half" (Orwell, p. 69)

So, the above text instances show that there cannot be seen any betterment in the lives of the animals. Animals do not feel any change in their lives. It is only a revolution that is produced due to the misanthropic behavior of the animals. The dream of the utopian world is only disillusionment. It is only revolt that can be seen against humans.

\section{Conclusion and Recommendations}

It can be concluded that in the speeches of Old Major, Napoleon, Squealer, Boxer, certain textual and stylistic devices have been used very repeatedly to attain some particulars objectives. They take all those requisites which a speech must have to propagate the beliefs in a sophisticated manner. It seems to be syntactically well-organized with frequent repetitions emphasizing the main theme which is inequality of socio-cultural rights and racial inequity based on powerful and powerless. The choices of the lexemes are not well ordered according to situation but also reviewing conditions and indicating the relational and expressive values of the speaker. Especially, Old Major and Napoleon very impressively and successfully with the help of metaphors and other devices discover the relationship between the powerful and oppressed. They very influentially thrive in realizing the force and support of the powerless without creating any conflict with the powerful.

Misanthropic perspectives have ascertained from the very speech of Old Major and nearly in every character of the novel. The elements of pessimism repress humans in a grievous and searing way.

The aim, desire, and expectation of the speaker can be opposed here. However, the animals' revolution cannot fulfill the anticipation. All the vices and evils that are found in the world also can be seen after the revolution of the animals. The Old Major is such character, who begins the cynical temperament against humans using the specific tone and attitude. The language that he uses in his address is very influential and draws long-lasting effects on the other character of the novel. Speaker uses grand diction seeing the emotions of the audience. In a very little time, using the different stylistic devices, he becomes the hero of the animals. All these perspectives lead towards a misanthropic attitude. The animals felt glad to see the humans suffering and distressing. These feelings are developed gradually at the end of the novel and their behavior and attitude against humans are become disgusting. The delusion of a utopian world cannot be accomplished. The facts of the dystopian world reveal the secret of vices and evils of the Farm. Animal Farm is the symbol and signs of cruelty, injustice, favoritism, hypocrisy, and flattery. All the possible wickedness is adopted by the animals to remove human beings from the earth. Animal's rude and harsh attitudes against humans compel them to repel the crown creature of the world from the Manor Farm. It is observed that all the things that are in the ownership of the humans are discarded in a much abhorrent manner. The findings of the paper have shown that the elements of misanthropic attitude that are discovered from the novel, the effects of misanthropic behavior on the characters of the novel, takes revolution against humans, and outcomes of the revolution illustrate the nightmarish and disillusionment world. 
It has also been explored in the present study that misanthropic behavior caused to lead animals for the revolution or rehabilitation in their lives and further has been analyzed the results of revolt in the lives of humans and animals. There are certain other factors like social cognition in their speeches which can be pointed out in further research. There are other approaches in CDA that can be applied to their speeches by keeping in view the same patterns. The models proposed by Van Dijk and Wodak can also be applied to carry out the qualitative nature of research.

\section{References}

Agamben, Giorgio. The Open: Man and Animal. Trans Kevin Attell. Stanford: Stanford UP, 2004. Print.

Burt, Jonathan. "Conflicts around Slaughter in Modernity" Animal Studies Group. Killing Animals. Urbana: U of Illinois P, 2006. 120-44. Print.

Hollis, Christopher. A Study of George Orwell. London: Hollis and Carter, 1956.Print.

H. G. Wells. Best Science Fiction Stories of H. G. Wells. New York. Dover, 1966.

Lee, Robert A. "The Uses of Form: A Reading of Animal Farm." Studies in Short Fiction 6 (1969): 557-73.Print.

McHugh, Susan. "Bringing up Babe." Camera Obscura 49 (2002): 149-87.

Mill, John Stuart. The Basic Writings of John Stuart Mill: On Liberty, The Subjection of Women and Utilitarianism. New York: Modern Library, 2002.

Orwell, George. Animal Farm. London: Penguin Books, 1999.Print.

Pearce, Robert. “Animal Farm.” History Today 55:8 (2005): 47-53.Print.

Rodden, John. "Appreciating Animal Farm in the New Millennium." Modern Age 45:1 (2003): 6777.Print.

Sedley, Stephen. “An Immodest Proposal: Animal Farm.” In Inside the Myth: Orwell: Views from the Left, edited by Christopher Norris. London: Lawrence \& Wishart, 1982.

Swift, Jonathan. A Modest Proposal and Other Satirical Works. New York: Dover, 1995.

Swift, Jonathan. Gulliver's Travels. London: Penguin Books, 2001.

Taylor, D.J. Orwell: The Life. New York: Henry Holt \& Co., 2003.Print.

Woodcock, George. The Crystal Spirit: A Study of George Orwell. Boston: Little, Brown, 1966.Print.

Wilde, Oscar. The Picture of Dorian Gray. In: The Complete Illustrated Work of Oscar Wilde. London. Bounty Books, 2006. 